\title{
STRES KERJA, LINGKUNGAN KERJA TERHADAP TURNOVER INTENTION PERUSAHAAN
}

\author{
Rutinaias Haholongan \\ Sekolah Tinggi Ilmu Ekonomi Indonesia (STEI Jakarta - Rawamangun) \\ rutinaias@gmail.com
}

JURNAL

MANAJEMEN

INDONESIA

\begin{abstract}
Abstrak
Diperlukan stress untuk meningkatkan kinerja karyawan, ketika seseorang mengejar ambisi dan beban kerja berlebihan yang terjadi timbullah distress yang menyebabkan karyawan berkeinginan mencari tempat kerja yang lain. Perputaran kerja dengan lingkungan kerja memiliki keterkaitan secara langsung. Kenyamanan atau ketidaknyamanan seorang karyawan terhadap lingkungan kerja dapat menumbuhkan rasa keinginan mencari tempat kerja yang lain. Penelitian ini bertujuan untuk menjelaskan apakah variabel stress kerja, lingkungan kerja,terhadap turnover intention karyawan. Analisa data dianalisis dengan metode Analisa Regresi Berganda dengan program software SPSS 19.0 for windows. Hasil penelitian menunjukkan bahwa variabel stress kerja berpengaruh terhadap turnover intention dan work environment berpengaruh terhadap turnover intention kinerja karyawan dengan pengaruh sebesar 0,512 .
\end{abstract}

Kata kunci : Stress Kerja, Lingkungan Kerja, Turnover Intention

\begin{abstract}
Stress is also needed to improve employee performance, when a person is pursuing ambition and excessive workload that occurs distress that causes employees to desire to find another workplace. Work cycle with work environment has direct link. Comfort or inconvenience of an employee to the work environment can foster a sense of desire to find another workplace. This study aims to explain whether the variable stress work, work environment, to employee turnover intention. Data analysis was analyzed by Multiple Regression Analysis method with SPSS 19.0 for windows software program. The results showed that work stress variables affect the turnover intention and work environment influence to employee turnover intention performance with the effect of 0,512 .
\end{abstract}

Keywords : Job Stress, Work Environment, Turnover Intention

\section{Pendahuluan}

Dalam pencapaian kesuksesan sebuah perusahaan, karyawan dianggap sebagai asset perusahaan. Sumber daya manusia begitu penting bagi perusahaan karena tidak dapat dipungkiri lagi bahwa tanpa adanya sumber daya manusia, kegiatan perusahaan tidak dapat dilaksanakan. Karena adanya hal tersebut maka sumber daya manusia pada perusahaan harus dikelola dan dipertahankan secara professional agar dapat mencapai tujuan bersama perusahaan dan juga memenuhi kebutuhan dari karyawan.

Robbins (2012) mengemukakan tiga alasan pentingnya manajemen sumber daya manusia bagi perusahaan: alasan pertama adalah manajemen sumber daya manusia dalam perusahaan bisa menjadi sumber yang signifikan bagi keunggulan kompetitif perusahaan. Kedua, manajemen sumber daya manusia menjadi bagian penting dari strategi organisasi. Terakhir adalah sumber daya manusia sangat mempengaruhi kinerja organisasi. Salah satu yang menjadi masalah dalam sebuah perusahaan terutama dalam era globalisasi adalah tingkat turnover yang tinggi. Turnover atau pergantian tenaga kerja dalam sebuah perusahaan adalah sebuah bentuk yang nyata dari sebuah turnover intention yang dapat menjadi masalah yang serius bagi perusahaan. Tingkat keseriusan dalam sebuah turnover akan semakin meningkat apabila tenaga kerja yang meninggalkan perusahaan adalah karyawan yang terampil dan 
mempunyai keahlian selalu dibutuhkan oleh perusahaan, atau bisa juga tenaga kerja yang mempunyai posisi vital pada perusahaan sehingga akan membuat keefektifitasan perusahaan akan terganggu.

Menurut Staffelbach (2008), turnover intention adalah sebuah keinginan dari individu dalam merubah pekerjaannya untuk melakukan pergantian tenaga kerja. Sedangkan pengertian lain mengenai turnover intention disampaikan oleh Mathis dan Jackson (2011) mengemukakan turnover intention itu adalah suatu proses ketika karyawan meninggalkan suatu organisasi dan meninggalkan suatu posisi pekerjaan dan dimana posisi tersebut harus digantikan oleh orang lain. Turnover intention yang tinggi mampu menghambat atau memperlambat perusahaan dari sisi finansial dan sisi hilangnya waktu dan kesempatan perusahaan dalam memanfaatkan sebuah peluang Stres kerja merupakan salah satu indikasi yang menyebabkan adanya turnover intention pada perusahaan. Sehingga stres kerja merupakan tekanan karyawan yang ada dalam perusahaan.

Indikasi lain yang mempengaruhi tingkat turnover intention adalah lingkungan kerja. Lingkungan kerja adalah faktor-faktor diluar dari karyawan dapat berupa fisik ataupun non fisik dalam sebuah perusahaan. Perusahaan harus memperhatikan lingkungan kerjanya agar dapat menciptakan suasana yang kondusif sehingga dapat melancarkan jalannya pekerjaan para karyawan. Karyawan dapat merasa tidak nyaman dalam bekerja apabila lingkungan dimana dia bekerja tidak membuatnya nyaman. Penerangan yang kurang atau berlebihan dapat mengganggu pandangan karyawan dalam bekerja, Temperatur ruangan kerja juga harus dijaga agar tidak terlalu panas ataupun tidak terlalu dingin sehingga karyawan merasa tidak merasa gerah ataupun tidak merasa kedinginan selama bekerja, dan kebisingan dalam ruangan kerja harus sangat dijaga karena dapat mengganggu konsentrasi karyawan dalam bekerja. Apabila tingkat kenyamanan karyawan dalam bekerja menurun maka karyawan akan merasa tidak betah dan memiliki keinginan untuk keluar.

Oleh karena itu, perusahaan harus sangat memperhatikan lingkungan kerja agar semua karyawanya merasa nyaman dalam menyelesaikan semua pekerjaan yang diberikan. Apabila karyawan merasa nyaman dalam bekerja maka hasil pekerjaan yang akan dihasilkan akan memuaskan, dan juga karyawan akan merasa nyaman dan betah bekerja di perusahaan tersebut.

Penelitian ini dilakukan sebagai pengembangan beberapa penelitian terdahulu, seperti pada penelitian dari Rizwan et al. (2014) hasil penelitian menyatakan terdapat pengaruh yang signifikan antara work stress dengan pergantian tenaga kerja. Menurut Rainayee (2013) menemukan bahwa stress kerja memiliki pengaruh signifikan turnover intention. Hasil dari penelitian ini menunjukkan bahwa turnover intention pada karyawan meningkat ketika mereka melihat adanya peluang alternatif eksternal dan mengalami stress kerja yang tidak semestinya di tempat kerja mereka.

Qureshi, Iftikhar, Abbas, Hassan, Khan, dan Zaman (2013) Terdapat hubungan yang signifikan antara lingkungan kerja dan turnover intention", menemukan bahwa lingkungan kerja dan turnover intention memiliki keterkaitan secara negatif satu sama lain. Pada penelitian nya Jamil et al. (2012) menemukan bahwa lingkungan kerja dan turnover intention terdapat pengaruh yang signifikan antara lingkungan kerja dan turnover intention. Tujuan penelitian adalah menguji dan menganalisis pengaruh stres kerja, lingkungan kerja terhadap turnover intention pada perusahaan manufaktur.

\section{Landasan Teori dan Metodologi}

\subsection{Turnover Intention}

Turnover Intention (Jacobs \& Roodt, 2007) merupakan sebuah keputusan mental atau psikis yang ada antara pendekatan individu dengan mengacu pada melanjutkan sebuah pekerjaan atau untuk meninggalkan sebuah pekerjaan. Menurut Horn dan Griffieth (1995) dalam Long dan Thean (2012), turnover intention didefinisikan sebagai perkiraan probabilitas pribadi karyawan bahwa ia memiliki maksud yang disengaja untuk meninggalkan organisasi secara permanen dalam waktu dekat. Menurut Lee (2008) dalam Varshney (2014), turnover intention didefinisikan sebagai perspektif subjektif dari anggota organisasi untuk keluar dari pekerjaannya saat ini untuk kesempatan lain. Sebagaimana penjelasan dari Lee, karyawan

Jurnal Manajemen Indonesia 
yang meninggalkan atas permintaan organisasi maupun orang - orang yang meninggalkan atas inisiatif sendiri dapat menyebabkan gangguan dalam operasi, dinamika tim kerja dan kinerja unit. Maka berdasarkan pengertian yang telah dikemukakan diatas, turnover intention adalah keinginan seseorang untuk meninggalkan perusahaan dan mencoba untuk mencari pekerjaan lain yang lebih baik dari sebelumnya.

\subsection{Stres Kerja}

Menurut Robbins (2012), stres adalah seorang yang dihadapkan tantangan, beban kerj dan tidak menghasilkan prestasi kerja. Sedangkan menurut Davis dan Newstrom (2008) mendefinisikan work stres yaitu seorang dihadapkan dengan berbagai macam masalah yang dapat mempengaruhi pola pikira dan tingkat emosional. Gejala umum seorang mengalami tingkat stress yang tinggi meliputi:

1. Gejala tingkah laku: perputaran karyawam bicara yang gagap, menimbulkan pusing kepala perubahan dalam metabolismeserta dapat menyebabkan serangan jantung.

2. Gejala kejiwaan: ketidakpuasan kondisi kerja, kejengkelan, kelebihan peran dan sikap suka menunda-nunda pekerjaan.

\subsection{Lingkungan Kerja}

Menurut Sedarmayanti (2013) lingkungan kerja yaitu pegawai senang beradaptasi melakukan pekerjaan, waktu kerja dipergunakan sangat efektif. Faktor - faktor mampu membentuk sebuah kondisi environmental work dengan kemampuan pegawai, meliputi:

a. Penerangan di lokasi kerja

b. Suhu di lokasi kerja

c. Kelembaban di lokasi kerja

d. Sirkulasi udara di lokasi kerja

e. Kebisingan di lokasi kerja.

g. Bau-bauan di lokasi kerja

h. Tata warna di lokasi kerja

Pada penelitian dari Rizwan et al. (2014) mendapatkan hubungan positif stress kerja dengan turnover intention. Menurut Rainayee (2013) menemukan bahwa turnover intention memiliki hubungan yang positif dan signifikan dengan Perceived Alternative Employment Opportunities (PAEO) dan stres kerja. Hasil dari penelitian ini menunjukkan bahwa turnover intention pada karyawan meningkat ketika mereka melihat adanya peluang alternatif eksternal dan mengalami stress kerja yang tidak semestinya di tempat kerja mereka.

Qureshi, Iftikhar, Abbas, Hassan, Khan, dan Zaman (2013) menemukan nilai p-value pada penelitian ini menunjukkan berepengaruh signifikan lingkungan kerja terhadap turnover intention. Penelitian ini membuktikan bahwa lingkungan kerja yang bagus dan sehat maka akan membuat tingkat pergantian tenaga kerja yang lebih rendah. Pada penelitian nya Jamil et al. (2012), menemukan bahwa lingkungan kerja berpengaruh negative terhadap turnover intention. Maka dari itu dapat dikatakan lingkungan kerja merupakan salah satu faktor untuk mempertahankan karyawan. Studi ini membuktikan bahwa lingkungan kerja yang baik dan sehat akan menuntun kearah berkurangnya intense karyawan untuk keluar dari pekerjaannya.

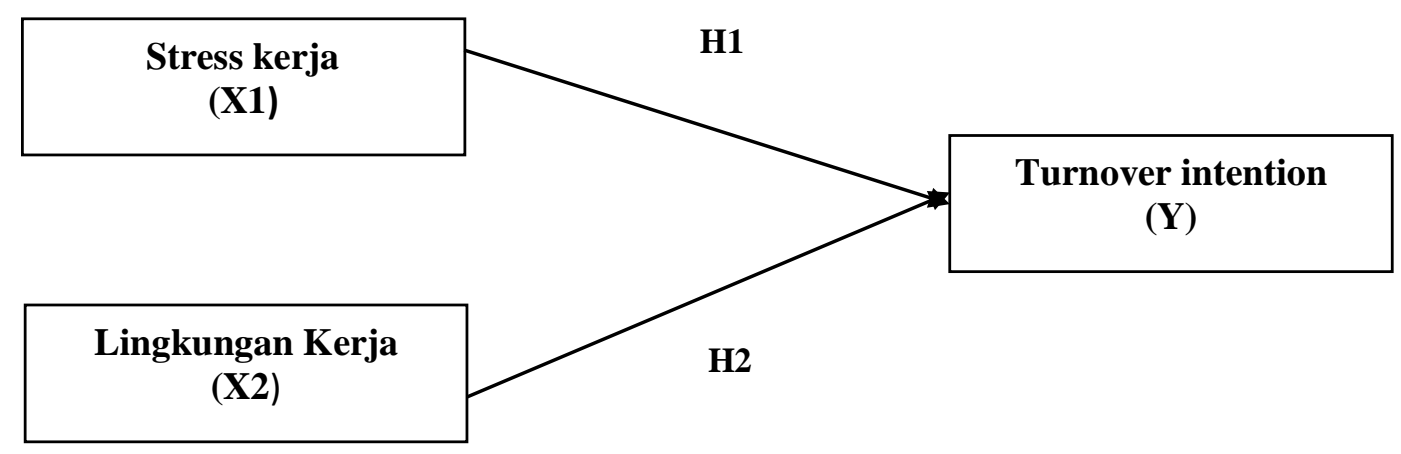

Gambar 1.

Kerangka Pemikiran 


\section{JURNAL}

\section{MANAJEMEN}

\section{INDONESIA}

\section{Vol.18 No.1}

April 2018

\section{Tabel 1.}

Pengukuran dan defi nisi operasional variabel penelitian

Sumber: Penulis (2018)
Dalam penelitian ini akan diuji hipotesis untuk memenuhi tujuan - tujuan yang ada dalam penelitian ini. Berikut ini merupakan hipotesis yang disusun dalam penelitian:

Hipotesis 1

H1: Terdapat pegaruh antara work stress terhadap pergantian tenaga kerja karyawan pada perusahaan

H2: Terdapat pengaruh antara work environmental terhadap pergantian tenaga kerja karyawan pada perusahaan

Penelitian ini menggunakan data primer. Metode penentuan sampel menggunakan metode convenience sampling yaitu metode yang membuat peneliti mengambil populasi dengan mudah. Analisis pendahuluan yang dilakukan adalah pengujian validitas dan uji reliabilitas data penelitian, serta pengujian regresi linear berganda dilakukan dengan software SPSS

\begin{tabular}{|c|c|c|c|c|}
\hline Variabel & Konsep Variabel & Dimensi & Jumlah Indikator & Literatur \\
\hline Stres kerja & $\begin{array}{l}\text { Merupakan respon } \\
\text { adaptif seseorang } \\
\text { untuk stimulus yang } \\
\text { menempatkan } \\
\text { tuntutan psikologis } \\
\text { atau tuntutan fisik } \\
\text { yang berlebihan pada } \\
\text { seseorang } \\
\text { tersebut }\end{array}$ & $\begin{array}{l}\text { - Konsekuensi } \\
\text { Individual } \\
\text { - Konsekuensi } \\
\text { Organisasi } \\
\text { - Kelelahan }\end{array}$ & $\begin{array}{l}\text { - } 7 \text { Indikator } \\
\text { - } 5 \text { Indikator } \\
\text { - } \quad 1 \text { indikator } \\
\text { Skala: skala } \\
\text { Likert dari } 1 \\
\text { sampai } 5 \text { poin. }\end{array}$ & $\begin{array}{l}\text { Moorhead \& } \\
\text { Griffin, 2013) }\end{array}$ \\
\hline $\begin{array}{l}\text { Lingkungan } \\
\text { Kerja }\end{array}$ & $\begin{array}{l}\text { Keseluruhan alat } \\
\text { perkakas } \\
\text { dan bahan yang } \\
\text { dihadapi } \\
\text { lingkungan } \\
\text { sekitarnya } \\
\text { dimana seseorang } \\
\text { bekerja, apa metode } \\
\text { kerjanya, serta } \\
\text { pengaturan kerjanya } \\
\text { baik } \\
\text { sebagai individu } \\
\text { maupun } \\
\text { kelompok }\end{array}$ & $\begin{array}{l}\text { - Fisik } \\
\text { - Non Fisik }\end{array}$ & $\begin{array}{l}\text { - } 1 \text { Indikator } \\
\text { - } 2 \text { Indikator } \\
\text { Skala: skala } \\
\text { Likert dari } 1 \\
\text { sampai } 5 \text { poin. }\end{array}$ & $\begin{array}{l}\text { (Sedarmayant } \\
\text { i, 2013) }\end{array}$ \\
\hline $\begin{array}{l}\text { Komitmen } \\
\text { Organisasi }\end{array}$ & $\begin{array}{l}\text { Komitmen organisasi } \\
\text { merupakan perasaan } \\
\text { yang kuat dari sebuah } \\
\text { loyalitas terhadap } \\
\text { organisasi dan } \\
\text { teridentifikasi melalui } \\
\text { organisasi itu sendiri }\end{array}$ & $\begin{array}{l}\text { - Identifikasi } \\
\text { - Usaha }\end{array}$ & $\begin{array}{l}\text { - } 4 \text { Indikator } \\
\text { - } 2 \text { Indikator } \\
\text { Skala: skala } \\
\text { Likert dari } 1 \\
\text { sampai } 5 \text { poin. }\end{array}$ & $\begin{array}{l}\text { Khanifar, } \\
\text { Hajlou, } \\
\text { Abdolhossein } \\
\text { i, Ataei, \& } \\
\text { Soltani, } \\
2012\end{array}$ \\
\hline
\end{tabular}

\section{Hasil dan Pembahasan}

Responden yang menjadi obyek penelitian ini berjumlah 124 responden Penyajian data ini bertujuan untuk memberikan gambaran tentang latar belakang para responden yang dijadikan masukan untuk memperjelas data penelitian yang meliputi jenis kelamin, usia dan pendidikan terakhir, masa kerja

Jurnal Manajemen Indonesia 


\begin{tabular}{|c|c|c|}
\hline Keterangan & Jumlah & Persentase \\
\hline \multicolumn{3}{|c|}{ Gender } \\
\hline Pria & 78 & 63 \\
\hline Wanita & 46 & 37 \\
\hline Jumlah & 124 & 100 \\
\hline \multicolumn{3}{|c|}{ Usia } \\
\hline 21-30 tahun & 38 & 31 \\
\hline 31 - 40 tahun & 67 & 54 \\
\hline 41-50 tahun & 19 & 15 \\
\hline Jumlah & 124 & 100 \\
\hline \multicolumn{3}{|c|}{ Pendidikan terakhir } \\
\hline SMP - SMA & 23 & 18 \\
\hline D1 - D3 & 32 & 26 \\
\hline $\mathrm{S} 1$ & 62 & 50 \\
\hline $\mathrm{S} 2-\mathrm{S} 3$ & 7 & 6 \\
\hline Jumlah & 124 & 100 \\
\hline \multicolumn{3}{|c|}{ Masa Kerja } \\
\hline$<1$ Tahun & 15 & 12 \\
\hline $1-5$ tahun & 58 & 47 \\
\hline $6-10$ tahun & 30 & 24 \\
\hline$>10$ tahun & 21 & 17 \\
\hline Jumlah & 124 & 100 \\
\hline
\end{tabular}

JURNAL

MANAJEMEN

INDONESIA

Vol.18 No.1

April 2018

Tabel 2.

Identitas Responden

Jika dilihat dari jenis kelamin sebanyak $63 \%$ responden berjenis kelamin laki-laki dan $37 \%$ berjenis kelamin perempuan. Jika dilihat dari tingkat usia 21-30 tahun sebanyak 31\% reponden,usia 31-40 tahun sebanyak54\% responden dan usia 41 - 50 tahun sebanyak 15\% pendidikan sebagian besar responden (50\%) memiliki tingkat pendidikan strata 1 (S1) dan sebagian kecil (6\%)memiliki tingkat pendidikan strata 2 (S2). Jika dilihat dari masa kerja, sebanyak $12 \%$ memiliki masa kerja < 1 tahun; sebanyak $47 \%$ memiliki masa kerja $1-5$ tahun, sebanyak 24\% memiliki masa kerja 6- 10 tahun; sebanyak 17\% memiliki masa kerja > 10 tahun.

\begin{tabular}{|l|c|c|}
\hline \multicolumn{1}{|c|}{ Keterangan } & $\begin{array}{c}\text { Cronbach's } \\
\text { Alpha }\end{array}$ & Keterangan \\
\hline Stres Kerja & 0.909 & Reliabel \\
\hline Lingkungan Kerja & 0.895 & Reliabel \\
\hline Turnover intention & 0.732 & Reliabel \\
\hline
\end{tabular}

Tabel 3.

Realibilitas

Dari hasil uji reliabilitas di atas variabel stress kerja, lingkungan kerja, turnover intention yang diketahui masing-masing variabel memiliki nilai reliabilitas (Cronbach's Alpha) di atas 0,60, maka dapat disimpulkan bahwa alat ukur dalam penelitian ini adalah reliable. 


\begin{tabular}{|l|l|r|r|}
\hline \multicolumn{1}{|c|}{ Variabel } & \multicolumn{1}{c|}{$\begin{array}{c}\text { Koefisien } \\
\text { Regresi }\end{array}$} & \multicolumn{1}{c|}{ Nilai t } & \multicolumn{1}{c|}{ Sig } \\
\hline Stres Kerja & 0.272 & 4.111 & 0.000 \\
Lingkungan Kerja & 0.563 & 9.059 & 0.000 \\
\hline Adjusted R square & 0.512 & \\
\cline { 2 - 4 } F hitung & 65.628 \\
\cline { 2 - 4 } Probabilitas F & 0.000 \\
\hline
\end{tabular}

\section{JURNAL}

\section{MANAJEMEN}

\section{INDONESIA}

Vol.18 No.1

April 2018

Tabel 4.

Ringkasan Hasil

Pengujian Analisis

Regresi Linier Berganda
Berdasarkan tabel diatas nilai adjusted square sebesar 0,512 artinya diketahui bahwa, variabel stres kerja, lingkungan kerja memiliki pengaruh pada variabel Turnover Intention (Y) sebesar $51 \%$. Nilai t sig stress kerja $0,000<0,05$ artinya stress kerja berpengaruh terhadap pergantian tenaga kerja. Hasil ini menunjukkan bahwa adanya peningkatan stres kerja karyawan dapat meningkatkan turnover intention karyawan. Hasil penelitian ini didukung dengan penelitian yang dilakukan oleh Rizwan et al. (2014) yang menyatakan bahwa stres kerja memiliki pengaruh yang signifikan terhadap turnover intention dengan pengaruh sebesar 73\%. Begitu pula dengan Rainayee (2013), menemukan bahwa stress kerja memiliki pengaruh signifikan turnover intention. Sementara lingkungan kerja nilai $t$ sig $0,000<0,05$ artinya lingkungan kerja berpengaruh terhadap stress kerja. Hasil ini menunjukkan bahwa peningkatan kondisi dan kualitas lingkungan kerja di perusahaan belum tidak ikut meningkatkan turnover intention karyawan. Hasil penelitian ini didukung dengan penelitian yang dilakukan oleh Qureshi et al. (2013) menemukan nilai p-value pada penelitian ini menunjukkan berepengaruh signifikan lingkungan kerja terhadap turnover intention. Penelitian ini membuktikan bahwa lingkungan kerja yang bagus dan sehat maka akan membuat tingkat turnover intention yang lebih rendah nilai probabilitas $\mathrm{F}$ yang didapat adalah sebesar 0,000 yang menunjukkan nilai yang lebih kecil dari 0,05 sehingga dapat diketahui stres kerja, lingkungan kerja berpengaruh secara bersama - sama terhadap turnover intention.

\section{Kesimpulan, Keterbatasan Penelitian dan Saran}

Simpulan yang dapat ditarik dari penelitian ini adalah sebagai berikut:

1. Terdapat pengaruh antara stres kerja terhadap turnover intention karyawan.

2. Terdapat pengaruh antara lingkungan kerja terhadap turnover intention karyawan

Dalam penelitian ini terdapat kekurangan dan keterbatasan yaitu:

1. Bagi peneliti selanjutnya, dianjurkan untuk mengambil variabel dan sampel penelitian yang berbeda dengan melibatkan beberapa variabel lain yang dapat mempengaruhi turnover intention seperti budaya perusahaan, gaya kepemimpinan, motivasi, kinerja karyawan.

2. Sasaran penelitian perlu menjangkau semua bagian perusahaan sehingga respondennya perlu ditambahkan

Berdasarkan kesimpulan diatas, saran yang dapat diberikan untuk perusahaan yaitu:

1. Dilihat dari hasil penelitian yang telah dilakukan, tingkat stres kerja harus tetap ditekan agar tidak melewati batas yang masih dapat ditoleransi oleh setiap karyawan karena seperti hasil penelitian penulis bahas, apabila tingkat stres kerja di perusahaan meningkat maka pergantian tenaga kerja karyawan di perusahaan juga akan meningkat.

2. Membuat lingkungan kerja fisik yang nyaman untuk karyawan dalam melaksanakan setiap pekerjaanya, membangun komunikasi dan hubungan yang baik dengan setiap individu baik itu sesama karyawan atau dengan atasan dengan meminimalisir jarak antara atasan dengan bawahan sehingga menciptakan lingkungan kerja non fisik yang harmonis. 


\section{Daftar Pustaka}

Davis, K., \& Newstrom, J. W. (2008). Jilid 1-2 Perilaku Dalam Organisasi. Jakarta: PT. Erlangga.

JURNAL

Jacobs, E., \& Roodt, G. (2007). The development of a knowledge sharing construct to predict turnover intentions. . Aslib Proceedings: New Information Perspectives, 319 - 337.

Jamil, A. R., Iftikhar, M., Arif, S., Qureshi, M. I., Lodhi, S., Naseem, I., et al. (2012). Job Stress, Workload, Environment and Employees Turnover Intentions: Destiny or Choice. Archives Des Sciences, 236.

Khanifar, H., Hajlou, M. H., Abdolhosseini, B., Ataei, F., \& Soltani, H. (2012). Factors Affecting the Organizational Commitment of Employees and Customer Satisfaction. Journal of Basic and Applied Scientific Research,11181.

Long, C. S., \& Thean, L. Y. (2012). Employees' Turnover Intention: A Leadership Issue?. International Journal of Future Computer and Communication, 1(3), 229.

Mathis, R. L., \& Jackson, J. H. (2011). Human Resource Management. USA: South- Western Cengage Learning.

Moorhead, G., \& Griffin, R. W. (2013). Perilaku Organisasi Manajemen Sumber Daya Manusia dan Organisasi. Jakarta: Salemba Empat.

Rainayee, R. A. (2013). Employee turnover intentions: Job stress or perceived alternative external opportunities. International Journal of Information, Business and Management, 5(1), 48.

Rizwan, M., Arshad, M. Q., Munir, H. M. A., Iqbal, F., \& Hussain, A. (2014). Determinants of Employees intention to leave: A Study from Pakistan. International Journal of Human Resource Studies, 4(3), 1.

Robbins, S. P. (2012). Perilaku Organisasi (15th Edition ed.). Jakarta: PT. Indeks.

Sedarmayanti. (2013). Sumber Daya Manusia dan Produktivitas Kerja. Bandung: CV Mandar Maju.

Staffelbach, B. (2008). Turnover Intent. Diploma Thesis. Departement: Strategieund Unternehmensökonomik .

Varshney, D. (2014). Impact of self-concept on turnover intention: An empirical study. American International Journal of Contemporary Research, 4(10), 87-96.

Qureshi, M. I., Iftikhar, M., Abbas, S. G., Hassan, U., Khan, K., \& Zaman, K. (2013). Relationship between job stress, workload, environment and employees turnover intentions: What we know, what should we know. World Applied Sciences Journal, 23(6), 764-770. 